\title{
Regulation of striatonigral prodynorphin peptides by dopaminergic agents
}

\author{
Keith A. Trujillo, Robert Day and Huda Akil \\ Mental Health Research Institute, The University of Michigan, Ann Arbor, MI 48109-0720 (U.S.A.)
}

(Accepted 21 November 1989)

Key words: Prodynorphin; Dynorphin; Enkephalin; Striatum; Substantia nigra; Hippocampus; Amphetamine; Haloperidol; Dopamine

\begin{abstract}
The primary purpose of this study was to examine the regulation of prodynorphin peptides by dopaminergic agents in the central nervous system. The indirectly acting catecholamine agonist D-amphetamine sulfate (AMPH) and the dopamine receptor antagonist haloperidol (HAL) were administered to rats across a variety of treatment schedules and drug doses. The striatum, substantia nigra and hippocampus were dissected and examined by radioimmunoassay for 5 different prodynorphin peptides, covering all 3 opioid domains in the prodynorphin precursor: dynorphin $\mathrm{A}(1-8)$ and dynorphin $\mathrm{A}(1-17)$ of the dynorphin $\mathrm{A}$ domain, dynorphin $\mathrm{B}(1-13)$ of the dynorphin $\mathrm{B}$ domain, and $\alpha$-neo-endorphin and $\beta$-neo-endorphin of the neo-endorphin domain. In addition, the proenkephalin peptide Met-enkephalin-arg ${ }^{6}$-gly ${ }^{7}-\mathrm{leu}^{8}$ (MERGL) was examined in the striatum. AMPH administered one hour prior to sacrifice caused a dose-dependent depletion of prodynorphin peptides in both the striatum and substantia nigra. In animals treated with AMPH once each day for 7 days and sacrificed $24 \mathrm{~h}$ later, a dramatic dose-dependent increase in prodynorphin peptides was observed in these brain regions. Animals treated with AMPH once each day for 7 days and sacrificed one hour after the final injection showed no changes in prodynorphin peptides. In addition to changes in individual prodynorphin peptides, AMPH treatment caused alterations in the relationships between intermediate peptides (dynorphin $A(1-17)$ and $\alpha$-neo-endorphin) and their immediate products (dynorphin $\mathrm{A}(1-8)$ and $\beta$-neo-endorphin). AMPH caused no consistent changes in prodynorphin peptides in the hippocampus, or in MERGL in the striatum. Taken together these data suggest that acute dopaminergic activation causes depletion of dynorphins from striatonigral prodynorphin neurons, presumably due to dopamine-dependent release of these peptides; repeated activation causes repeated release, with a rebound increase in biosynthesis. HAL, in contrast to AMPH caused relatively subtle changes in striatonigral prodynorphin peptides. Although no significant changes in individual prodynorphin peptides were observed, HAL treatment caused a change in the relationship between dynorphin $\mathrm{A}(1-17)$ and dynorphin $\mathrm{A}(1-8)$, a change opposite in direction to that observed with AMPH treatment. As has been previously reported, repeated HAL administration caused a dose-dependent increase in the proenkephalin peptide MERGL. The relatively subtle effects of HAL on prodynorphin peptides suggests that tonic dopamine activity is not important in the regulation of striatonigral prodynorphin neurons. The potential functional and behavioral significance of the present results are discussed.
\end{abstract}

\section{INTRODUCTION}

The dynorphin family is the most recently discovered of the endogenous opioid peptides ${ }^{8,17,29}$, and is thus less well-understood than the pro-opiomelanocortin or proenkephalin families. This family of peptides is a product of the prodynorphin (Prodyn) precursor which codes for 3 opioid peptide domains: the neo-endorphin domain (Neo Endo), the dynorphin A domain (Dyn A) and the dynorphin B domain (Dyn B), each of which contains the amino acid sequence for Leu-enkephalin at their $\mathrm{N}$ terminus (Tyr-Gly-Gly-Phe-Leu). These domains are flanked by pairs of basic amino acid residues (lysine or arginine) at which trypsin-like and carboxypeptidase B-like action can occur, yielding the opioid peptides $\alpha$-Neo Endo, Dyn $\mathrm{A}(1-17)$ and leumorphin, respectively ${ }^{11}$. In addition, further cleavage can give rise to smaller opioid peptides: $\beta$-Neo Endo from $\alpha$-Neo Endo $^{39}$, Dyn A(1-8) from Dyn A(1-17) ${ }^{40,56}$ and Dyn B from leumorphin ${ }^{29,43}$. Recent evidence suggests that Leu-enkephalin might also be a product of the Prodyn precursor $^{7,64}$. The Prodyn precursor can thus produce a variety of neuroactive opioid peptides. Despite this knowledge of the Prodyn precursor and its putative products, little is known of the regulation of Prodyn systems in the brain, including which particular products are released and how these systems might respond to various challenges.

The nigrostriatal-striatonigral system is one of the most widely studied neural systems in the brain and is consequently relatively well understood in terms of anatomy, physiology, pharmacology and behavior ${ }^{12,19,47}$. A primary feature of the nigrostriatal system is dopamine neurons densely arranged in the substantia nigra pars compacta. These neurons have dendrites in the substantia nigra pars reticulata and send terminals to the striatum. The dopamine terminals in the striatum can innervate interneurons within this nucleus, or directly innervate

Correspondence: K.A. Trujillo, Mental Health Research Institute, The University of Michigan, Ann Arbor, MI 48109-0720, U.S.A. 
long projection neurons that send terminals back to the substantia nigra ${ }^{32-35}$. A dense Prodyn projection with cell bodies in the striatum and terminals in the substantia nigra pars reticulata has been identified ${ }^{14,38,46,61,65}$. As can readily be seen, this arrangement provides the architecture for a nigrostriatal-striatonigral neuronal loop whereby dopamine can influence Prodyn neuronal activity, and Prodyn peptides can, in return, influence dopamine neuron activity. This system therefore provides a unique opportunity to study Prodyn expression in the brain and its modification by pharmacological manipulations.

Although some studies have begun to examine the regulation of striatonigral Prodyn peptides by dopaminergic agents, these studies have been somewhat limited in their analyses. First, most published studies to date have used limited drug doses and/or injection schedules and have thus provided little information about the pharmacology of the drug effects. Second, these studies have typically examined only a single prodynorphin peptide (using antisera directed against either Dyn A(1-8), Dyn A(1-17) or Dyn B) thus offering little insight into possible changes in processing associated with drug treatments, and raising the possibility that different Prodyn domains may respond differently to dopaminergic treatment. To date there appears to be consensus that repeated administration of dopamine agonists will increase content of striatonigral Prodyn peptides ${ }^{22,36,48}$. In contrast, there is disagreement over the effects of dopamine antagonists. While some investigators have reported increases in peptide content following repeated treatment with antagonists ${ }^{51}$, others have reported slight decreases ${ }^{45}$, or no effects ${ }^{36,48}$.

In the present study we examined the effects of acute and repeated amphetamine or haloperidol injections on Prodyn peptides in the striatum and substantia nigra. Amphetamine is an indirect acting catecholamine agonist, which stimulates release of catecholamines, blocks their reuptake, and inhibits the metabolic enzyme monoamine oxidase. Although amphetamine has important actions on both dopamine and norepinephrine neurons, norepinephrine is much less concentrated than dopamine in the striatum (see ref. 19), and appears to play an insignificant role in amphetamine-induced effects in the nigrostriatal system (see refs. 31, 42). Haloperidol is a competitive dopamine receptor antagonist. Our primary purpose was to study the regulation of Prodyn peptides in a well-understood CNS system. In addition, we hoped to obtain information about the neurochemical actions of amphetamine and haloperidol that might be important in understanding their behavioral effects. Multiple drug doses $(1.0,5.0$ and $10 \mathrm{mg} / \mathrm{kg}$ for amphetamine, and 0.25 , $0.5,1.0$ and $2.0 \mathrm{mg} / \mathrm{kg}$ for haloperidol) and injection schedules (acute, chronic with no rest, and chronic with rest) were utilized. We were thus able to examine dose-response curves as well as acute versus chronic effects of drugs. In addition, 5 different prodynorphin peptide products were examined by radioimmunoassay, encompassing all 3 opioid domains in the prodynorphin precursor: Dyn $A(1-8)$ and Dyn $A(1-17)$ of the Dyn $A$ domain; Dyn B(1-13) of the Dyn B domain; and $\alpha$-Neo Endo and $\beta$-Neo Endo of the Neo Endo domain. We were therefore able to obtain information about the striatonigral Prodyn system as a whole, rather than focusing on one particular peptide or peptide domain in the Prodyn precursor. The hippocampus was examined as an anatomical control - this brain region is rich in Prodyn products, is outside the striatonigral pathway and is under little dopaminergic influence. For neurochemical comparison Met-enkephalin-arg ${ }^{6}$-gly -leu $^{8} \quad$ (MERGL) was examined in the striatum - this peptide is a product of the proenkephalin molecule, is found in high concentrations in the striatum, and is regulated differently than prodynorphin.

Beyond the simple demonstrations of changes in peptide levels following pharmacological manipulations, very little is known about more specific dynamic issues concerning the Prodyn peptides in the striatonigral system (or for that matter, in the brain in general). More information is necessary to begin to understand the regulation of these peptides in the CNS. An important feature of the present studies is the examination of both Dyn $\mathrm{A}(1-8)$ and Dyn $\mathrm{A}(1-17)$, and both $\beta$-Neo Endo and $\alpha$-Neo Endo. Dyn $A(1-17)$ can be viewed as the immediate precursor of Dyn $\mathrm{A}(1-8)$, and $\alpha$-Neo Endo can be viewed as the immediate precursor of $\beta$-Neo Endo. Alterations in these 'precursor-product' relationships can give valuable information about the dynamic status of the Prodyn system, including clues about changes in biosynthesis, processing or release.

\section{MATERIALS AND METHODS}

Animals. Adult male Sprague-Dawley rats were used for all experiments. Animals were housed in groups of 5-7 in stainless steel cages on a 12-h light/dark cycle. Food and water was available ad libitum.

Experimental design. Animals (5-7 per group) were weighed each day of the experiment and drug or vehicle was injected subcutaneously (s.c.) or intraperitoneally (i.p.). In the first series of experiments animals were treated s.c. with $1 \mathrm{ml} / \mathrm{kg}$ of $0.9 \%$ saline, or D-amphetamine sulfate (Sigma Chemical Co.) dissolved in saline. In these experiments 3 different injection schedules were used: acute, in which animals were sacrificed $1 \mathrm{~h}$ after a single injection of drug or vehicle; 7 days-no rest, in which animals were given a single injection each day for 7 days and sacrificed $1 \mathrm{~h}$ after the final injection; and 7 days with rest, in which animals were given a single injection each day for 7 days and sacrificed $24 \mathrm{~h}$ after the final injection. In the second series of experiments animals were treated with Haldol (McNeil Pharmaceutical) or bacteriostatic water for 
injection, USP (Invenex Laboratories). The injection schedules used in these experiments included: acute, as described above; 4 days-no rest, in which animals received a single $i . p$. injection each day for 4 days and were sacrificed $1 \mathrm{~h}$ after the final injection; 4 days with rest, in which animals received a single i.p. injection each day for 4 days and were sacrificed $24 \mathrm{~h}$ after the final injection; and 15 days with rest, in which animals received a single s.c. injection each day for 15 days and were sacrificed $24 \mathrm{~h}$ after the final injection. Injections were performed at the same time each morning, counterbalancing the various groups to minimize circadian influences. Following the appropriate treatment rats were sacrificed by decapitation and the striatum, substantia nigra and hippocampus rapidly dissected on ice. Tissue was immediately frozen on dry ice and kept at $-80^{\circ} \mathrm{C}$ until further processed.

Extraction of tissue. For extraction of peptides, frozen tissue from individual animals was quickly weighed and then homogenized in 1 ml of ice-cold methanol:0.1 $\mathrm{N} \mathrm{HCl}(\mathrm{MeOH}: \mathrm{HCl} ; 1: 1 \mathrm{v} / \mathrm{v})$ with a Brinkman Polytron. The Polytron was washed with $1 \mathrm{ml}$ of ice-cold $\mathrm{MeOH}: \mathrm{HCl}$ and the wash added to the homogenate. The suspended tissue was centrifuged for $20 \mathrm{~min}$ at $15,000 \mathrm{rpm}$, the pellet discarded, and the supernatant dried under vacuum (Savant Speed Vac). The dried extract was redissolved in $1 \mathrm{ml}$ of $\mathrm{MeOH}: \mathrm{HCl}$ and aliquots diluted to appropriate concentrations for radioimmunoassay. Samples were stored at $-20{ }^{\circ} \mathrm{C}$ until assayed

Gel chromatography. Gel filtration chromatography was performed on selected experimental and control groups. A 250- $\mu$ l aliquot was taken from the extracted sample of each animal, pooled according to experimental group, lyophilized, and resuspended in $1.5 \mathrm{ml}$ of $1 \%$ formic acid with $0.01 \%$ bovine serum albumin (FA/BSA). A $250-\mu$ l aliquot was taken from the pooled samples and the remaining $1.25 \mathrm{ml}$ applied to a Sephadex G-50-50 (Sigma Chemical Co.) superfine column $(1.5 \times 90 \mathrm{~cm}$, Pharmacia $)$. The column was eluted with FA/BSA and collected in 2-ml fractions. Fractions and pooled sample aliquots were lyophilized and resus pended in $\mathrm{MeOH}: \mathrm{HCl}$ to appropriate concentration for radioimmunoassay. The gel filtration column was calibrated with blue dextran for determination of the void volume $(\mathrm{mw}>2,000 \mathrm{kDa})$, cobalt chloride for determination of the total volume ( $\mathrm{mw}=0.1$ $\mathrm{kDa}$ ), and bovine $\alpha$-lactalbumin ( $\mathrm{mw}=14.2 \mathrm{kDa}$ ), bovine lung aprotinin ( $\mathrm{mw}=6.5 \mathrm{kDa}$ ) and insulin b-chain oxidized ( $\mathrm{mw}=3.5$ $\mathrm{kDa}$ ) for molecular weight standards.

Radioimmunoassays. Radioimmunoassays (RIA's) were carried out in sodium phosphate buffer $(150 \mathrm{mM}, \mathrm{pH} 7.3$, containing $0.9 \%$ sodium chloride, $0.1 \%$ bovine serum albumin, and $0.01 \%$ sodium azide), in a total volume of $300 \mu 1$ ( $100 \mu$ l of tissue sample or peptide standard dissolved in $\mathrm{MeOH}: \mathrm{HCl}, 100 \mu \mathrm{l}$ of ${ }^{125}$ I-labeled peptide diluted to $10,000 \mathrm{cpm}$ in RIA buffer, and $100 \mu \mathrm{l}$ of antiserum diluted to appropriate concentration in RIA buffer). After overnight incubation at $4^{\circ} \mathrm{C}$, the reaction was terminated by addition of 0.6 $\mathrm{ml}$ of charcoal slurry $(5 \mathrm{~g}$ of decolorizing carbon, $300 \mu \mathrm{g}$ of dextran, MW 77,800, and $15 \mathrm{ml}$ of swine serum, in $100 \mathrm{ml}$ of $150 \mathrm{mM}$ sodium phosphate buffer, pH 7.3) and centrifuged for $15 \mathrm{~min}$ at 7,000 $\mathrm{g}$. The pellet was discarded and the supernatant counted in a TM Analytic 1290 gamma counter. All assays were performed in triplicate.

Labeled peptides for radioimmunoassay were prepared by chloramine-T-mediated iodination. Iodination mixtures were applied to Sep Pak $\mathrm{C} 18$ cartridges, washed with $0.1 \%$ trifluoroacetic acid (TFA), and eluted with $60 \%$ acetonitrile in $0.1 \%$ TFA. The iodinated peptides were then purified by HPLC using a Waters $\mu$-Bondapak C18 reverse phase column, eluting with a linear gradient of $15-40 \%$ acetonitrile in $60 \mathrm{~min}$. Dyn $\mathrm{A}(1-8)$ was purchased from Peninsula Laboratories, Dyn A(1-17) from Peninsula Laboratories or Bachem, $\alpha$-Neo Endo from Bachem, and Dyn $B$ was a gift from D.H. Coy. Antisera for RIA were raised in our laboratory by immunizing rabbits with thyroglobulin-conjugated peptides $^{62}$, except the $\beta$-Neo Endo antiserum which was a gift from C.J. Evans of Stanford University. Dyn A(1-17) antiserum (\#54; $1: 100,000$ final dilution in the RIA) was raised against synthetic Dyn $A(1-17)$ and is directed against the COOH-terminus of this peptide. The $\mathrm{IC}_{50}$ of this assay is approximately $10 \mathrm{fmol} / \mathrm{tube}$. This antiserum has less than $0.001 \%$ cross-reactivity with Dyn A(1-8), Leuenkephalin, or $\alpha$-Neo Endo. Dyn A(1-8) antiserum (\#73; $1: 230,000$ final dilution) is directed against the $\mathrm{COOH}-t$ rminal region of the molecule. This antiserum has less than $0.001 \%$ cross-reactivity with Dyn A(1-17), Dyn B or Leu-cnkephalin and less than $0.01 \%$ cross-reactivity with $\alpha$-Neo Endo. The IC $\mathrm{C}_{\text {s }}$ of this assay is approximately $6 \mathrm{fmol} / \mathrm{tube}$. Dyn B antiserum ( \#94; final dilution 1:50,000) was raised against synthetic Dyn $B$ and is C-terminusdirected. This antiserum is approximately $0.002 \%$ cross-reactive with Dyn $\mathrm{A}(1-8)$, less than $0.001 \%$ cross-reactive with Dyn $\mathrm{A}(1-17)$ or $a-\mathrm{Neo}$ Endo, and has an $\mathrm{IC}_{50}$ of approximately $15 \mathrm{fmol} / \mathrm{tube}$. $\alpha$-Neo Endo antiserum ( $\# 59 ; 1: 27,000$ final dilution) is $\mathrm{COOH}$ terminus directed, has $0.1 \%$ cross-reactivity with $\beta$-Neo Endo, less than $0.001 \%$ cross-reactivity with Dyn A(1-8), Dyn A(1-17), Dyn $\mathrm{B}$ and Leu-enkephalin, and has an $\mathrm{IC}_{50}$ of $80 \mathrm{fmol} / \mathrm{tube}$. $\beta$-Neo Endo antiserum (C.J. Evans; 1:12,000 final dilution) has less than $0.01 \%$ cross-reactivity with $\alpha$-Neo Endo, no detectable crossreactivities Dyn $\mathrm{A}(1-8)$, Dyn $\mathrm{A}(1-17)$, Leu-enkephalin, or Metenkephalin, and an $\mathrm{IC}_{50}$ of approximately $6 \mathrm{~mol} / \mathrm{tube}$. MERGL antiserum (\#55; 1:1000 final dilution) has an $\mathrm{IC}_{50}$ of approximately $120 \mathrm{fmol} /$ tube.

Data analysis. For statistical purposes, drug effects were examined by analysis of variance, followed by Dunnet's $t$-test for post-hoc analysis. Where appropriate, effects were compared by Student's $t$-test. 'Precursor-product' relationships were determined by dividing the content of the product (Dyn $A(1-8)$ or $\beta$-Neo Endo) by the content of the intermediate peptide (Dyn $A(1-17)$ or $\alpha$-Neo Endo) for each animal and determining the mean and standard error for the group.

\section{RESULTS}

Effects of acute amphetamine injection on Prodyn peptides. Animals sacrificed $1 \mathrm{~h}$ following a single injection of amphetamine (1.0, 5.0 or $10.0 \mathrm{mg} / \mathrm{kg}$ ) showed dose-dependent changes in content of all 5 Prodyn peptides when compared with saline control

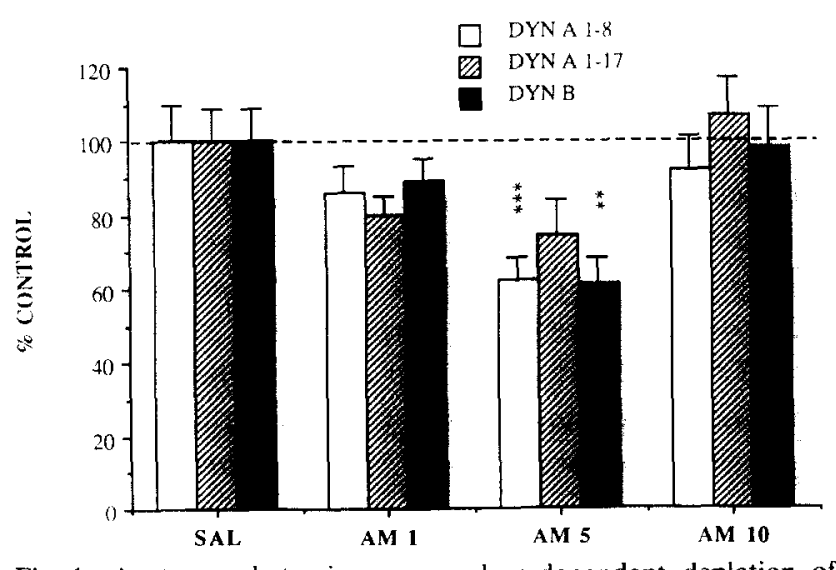

Fig. 1. Acute amphetamine causes dose-dependent depletion of striatal prodynorphin peptides. Saline (SAL) or D-amphetamine sulphate $(\mathrm{AM} ; 1.0,5.0$ or $10 \mathrm{mg} / \mathrm{kg}$ ) was administered $1 \mathrm{~h}$ prior to sacrifice and peptide concentrations were determined by radioimmunoassay. Values are expressed as mean percent control \pm S.E.M., $n=6$ animals per treatment. Significant differences from saline control were determined by analysis of variance followed by Dunnet's $t$-test for post-hoc comparisons: ${ }^{*} P<0.05$, ${ }^{*} P<0.01$, ${ }_{* * *} P<0.005$ different from saline control as revealed by Dunnet's $t$-test. Similar effects were observed for all 5 prodynorphin peptides in the striatum, as well as in substantia nigra (see Table I). 
TABLE I

Effects of acute amphetamine treatment on peptides in striatum, substantia nigra and hippocampus

Animals ( $n=6$ per group) received a single s.c. injection of saline (SAL) or D-amphetamine sulfate (AM; $1.0,5.0 \mathrm{or} 10.0 \mathrm{mg} / \mathrm{kg}$ ) $1 \mathrm{~h} \mathrm{prior}$ to sacrifice. ${ }^{*} P<0.05,{ }^{* *} P<0.01,{ }^{* * *} P<0.005$. Values are expressed as $\mathrm{pmol} / \mathrm{g}$ wet $\mathrm{wt} . \pm \mathrm{S}$. E.M. Values in parentheses are percent control \pm S.E.M.

\begin{tabular}{|c|c|c|c|c|}
\hline & $S A L$ & $A M 1$ & $A M 5$ & AM 10 \\
\hline \multicolumn{5}{|l|}{ Striatum } \\
\hline Dyn A(1-8) & $\begin{array}{l}54.7 \pm 5.2 \\
(100 \pm 9.6)\end{array}$ & $\begin{array}{c}47.3 \pm 3.7 \\
(86 \pm 6.8)\end{array}$ & $\begin{array}{c}34.0 \pm 3.0^{* * *} \\
(62 \pm 5.5)\end{array}$ & $\begin{array}{c}50.1 \pm 5.0 \\
(92 \pm 9.1)\end{array}$ \\
\hline Dyn A(1-17) & $\begin{array}{l}13.9 \pm 1.2 \\
(100 \pm 8.7)\end{array}$ & $\begin{array}{c}11.0 \pm 0.7 \\
(80 \pm 5.1)\end{array}$ & $\begin{array}{c}10.4 \pm 1.4 \\
(74 \pm 9.9)\end{array}$ & $\begin{array}{l}14.9 \pm 1.4 \\
(107 \pm 10)\end{array}$ \\
\hline Dyn B & $\begin{array}{l}33.8 \pm 3.2 \\
(100 \pm 9.4)\end{array}$ & $\begin{array}{c}30.0 \pm 2.2 \\
(89 \pm 6.5)\end{array}$ & $\begin{array}{c}20.7 \pm 2.5^{* *} \\
(61 \pm 7.4)\end{array}$ & $\begin{array}{c}33.2 \pm 3.8 \\
(98 \pm 11.2)\end{array}$ \\
\hline$\alpha$-Neo Endo & $\begin{array}{l}94.0 \pm 7.1 \\
(100 \pm 7.5)\end{array}$ & $\begin{array}{r}84.0 \pm 6.0 \\
(89 \pm 6.4)\end{array}$ & $\begin{array}{c}67.2 \pm 10.3 \\
(71 \pm 11.0)\end{array}$ & $\begin{array}{c}91.6 \pm 7.8 \\
(97 \pm 8.2)\end{array}$ \\
\hline$\beta$-Neo Endo & $\begin{array}{c}2.0 \pm 0.25 \\
(100 \pm 12.5)\end{array}$ & $\begin{array}{l}1.7 \pm 0.17 \\
(85 \pm 8.4)\end{array}$ & $\begin{array}{l}1.3 \pm 0.15 \\
(67 \pm 7.7)\end{array}$ & $\begin{array}{c}2.0 \pm 0.30 \\
(101 \pm 14.8)\end{array}$ \\
\hline MERGL & $\begin{array}{c}244 \pm 22.5 \\
(100 \pm 9.2)\end{array}$ & $\begin{array}{c}248 \pm 8.4 \\
(101 \pm 3.5)\end{array}$ & $\begin{array}{l}209 \pm 16.0 \\
(85 \pm 6.5)\end{array}$ & $\begin{array}{c}247 \pm 19.8 \\
(101 \pm 8.1)\end{array}$ \\
\hline \multicolumn{5}{|c|}{ Substantia nigra } \\
\hline Dyn $A(1-8)$ & $\begin{array}{c}129.3 \pm 10.8 \\
(100 \pm 8.4)\end{array}$ & $\begin{array}{r}105.4 \pm 11.4 \\
(82 \pm 8.8)\end{array}$ & $\begin{array}{c}111.0 \pm 12.4 \\
(86 \pm 9.6)\end{array}$ & $\begin{array}{r}159.7 \pm 45.0 \\
(124 \pm 34.8)\end{array}$ \\
\hline Dyn A(1-17) & $\begin{array}{l}36.6 \pm 3.4 \\
(100 \pm 9.4)\end{array}$ & $\begin{array}{c}32.2 \pm 2.1 \\
(88 \pm 5.9)\end{array}$ & $\begin{array}{c}33.6 \pm 2.0 \\
(92 \pm 5.4)\end{array}$ & $\begin{array}{l}51.0 \pm 12.0 \\
(139 \pm 32.7)\end{array}$ \\
\hline Dyn B & $\begin{array}{r}162.9 \pm 21.8 \\
(100 \pm 13.3)\end{array}$ & $\begin{array}{r}141.4 \pm 12.1 \\
(87 \pm 7.5)\end{array}$ & $\begin{array}{r}138.0 \pm 9.9 \\
(85 \pm 6.0)\end{array}$ & $\begin{array}{c}205.6 \pm 50.1 \\
(126 \pm 30.8)\end{array}$ \\
\hline$\alpha$-Neo Endo & $\begin{array}{r}551 \pm 26.5 \\
(100 \pm 4.8)\end{array}$ & $\begin{array}{l}491 \pm 28.0 \\
(89 \pm 5.0)\end{array}$ & $\begin{array}{l}519 \pm 47.2 \\
(94 \pm 8.5)\end{array}$ & $\begin{array}{c}689 \pm 111.3 \\
(125 \pm 20.1)\end{array}$ \\
\hline$\beta$-Neo Endo & $\begin{array}{l}10.1 \pm 1.3 \\
(100 \pm 13.3)\end{array}$ & $\begin{array}{c}8.8 \pm 1.0 \\
(86.4 \pm 10.2)\end{array}$ & $\begin{array}{c}7.4 \pm 0.9 \\
(73.4 \pm 9.1)\end{array}$ & $\begin{array}{l}13.7 \pm 5.0 \\
(135 \pm 49.1)\end{array}$ \\
\hline \multicolumn{5}{|l|}{ Hippocampus } \\
\hline Dyn A(1-8) & $\begin{array}{l}11.6 \pm 1.5 \\
(100 \pm 12.8)\end{array}$ & $\begin{array}{l}12.6 \pm 1.4 \\
(109 \pm 11.6)\end{array}$ & $\begin{array}{l}12.6 \pm 2.2 \\
(108 \pm 18.7)\end{array}$ & $\begin{array}{l}9.8 \pm 0.5 \\
(84 \pm 4.6)\end{array}$ \\
\hline Dyn A(1-17) & $\begin{array}{l}19.3 \pm 3.4 \\
(100 \pm 17.4)\end{array}$ & $\begin{array}{l}19.0 \pm 3.0 \\
(98 \pm 15.5)\end{array}$ & $\begin{array}{c}18.8 \pm 2.7 \\
(98 \pm 14.1)\end{array}$ & $\begin{array}{l}19.6 \pm 2.2 \\
(101 \pm 11.5)\end{array}$ \\
\hline Dyn B & $\begin{array}{l}33.6 \pm 3.2 \\
(100 \pm 9.5)\end{array}$ & $\begin{array}{c}33.3 \pm 2.9 \\
(99 \pm 8.9)\end{array}$ & $\begin{array}{c}30.8 \pm 4.5 \\
(92 \pm 13.5)\end{array}$ & $\begin{array}{c}29.0 \pm 1.9 \\
(86 \pm 5.5)\end{array}$ \\
\hline$\alpha$-Neo Endo & $\begin{array}{l}50.6 \pm 7.2 \\
(100 \pm 14.2)\end{array}$ & $\begin{array}{l}46.2 \pm 6.8 \\
(91 \pm 13.5)\end{array}$ & $\begin{array}{l}47.4 \pm 9.6 \\
(94 \pm 19.0)\end{array}$ & $\begin{array}{c}35.2 \pm 5.7 \\
(70 \pm 11.3)\end{array}$ \\
\hline
\end{tabular}

animals. In the striatum, a U-shaped dose-response was observed, with apparent decreases occurring at 1.0 and $5.0 \mathrm{mg} / \mathrm{kg}$, and no changes at $10.0 \mathrm{mg} / \mathrm{kg}$. Analysis of variance revealed a significant effect for Dyn $A(1-8)$, Dyn A(1-17) and Dyn B (Fig. 1, Table I). While changes in $\alpha$-Neo Endo and $\beta$-Neo Endo were similar in both the magnitude and the pattern of response, these effects were not statistically significant. In the substantia nigra a similar U-shaped pattern was observed, although smaller in magnitude and not statistically significant (Table I). No effects of acute amphetamine were observed on any Prodyn peptide in the hippocampus or on MERGL in the striatum (Table I).

Effects of repeated amphetamine injections on Prodyn peptides. Animals given a single injection of amphetamine $(1.0,5.0$ or $10.0 \mathrm{mg} / \mathrm{kg})$ once per day for 7 days, and sacrificed $24 \mathrm{~h}$ following the final injection ( 7 days-rest), showed dramatic dose-dependent increases in striatonigral Prodyn peptides in comparison with saline control animals. Analysis of variance revealed a significant effect for all Prodyn peptides except $\beta$-Neo Endo in the striatum, and for Dyn A(1-8), Dyn A(1-17) and Dyn $B$ in the substantia nigra (Fig. 2, Table II). No effects of repeated amphetamine injections were observed on any Prodyn peptide in the hippocampus or on MERGL in the striatum (Table II).

The concentration of $\alpha$-Neo Endo was observed to be considerably higher, and the amphetamine response (when expressed as percent control) considerably smaller than other Prodyn peptides (Table II). In order to further examine these findings, molecular sieving on a G-50 sephadex column, followed by radioimmunoassay, was performed on the saline and $10 \mathrm{mg} / \mathrm{kg}$ groups. Approximately $90 \%$ of $\alpha$-Neo Endo-immunoreactive material 
TABLE II

Effects of repeated amphetamine treatment on peptides in striatum, substantia nigra and hippocampus

Animals $(n=6$ per group) received a single s.c. injection of saline (SAL), or D-amphetamine sulfate (AM; $1.0,5.0 \mathrm{or} 1.0 \mathrm{mg} / \mathrm{kg}$ ) once each day for 7 days and were sacrificed $24 \mathrm{~h}$ after the final injection. ${ }^{*} P<0.05,{ }^{* *} P<0.01,{ }^{* * *} P<0.005$. Values are expressed as pmol/g wet wt. $\pm \mathrm{S}$. E.M. Values in parentheses are percent control \pm S.E.M.

\begin{tabular}{|c|c|c|c|c|}
\hline & $S A L$ & $A M I$ & $A M 5$ & $A M 10$ \\
\hline \multicolumn{5}{|l|}{ Striatum } \\
\hline Dyn $A(1-8)$ & $\begin{array}{l}15.0 \pm 1.5 \\
(100 \pm 10.0)\end{array}$ & $\begin{array}{l}17.5 \pm 2.0 \\
(117 \pm 13.6)\end{array}$ & $\begin{array}{l}21.0 \pm 2.1 \\
(140 \pm 13.8)\end{array}$ & $\begin{array}{l}32.3 \pm 6.7^{* *} \\
(216 \pm 44.5)\end{array}$ \\
\hline Dyn A(1-17) & $\begin{array}{c}2.5 \pm 0.6 \\
(100 \pm 25.5)\end{array}$ & $\begin{array}{c}3.6 \pm 0.9 \\
(141 \pm 33.7)\end{array}$ & $\begin{array}{c}7.0 \pm 0.7^{* *} \\
(276 \pm 26.0)\end{array}$ & $\begin{array}{l}8.0 \pm 1.4^{* * *} \\
(316 \pm 56.9)\end{array}$ \\
\hline Dyn B & $\begin{array}{l}20.1 \pm 3.1 \\
(100 \pm 15.5)\end{array}$ & $\begin{array}{l}34.6 \pm 8.9 \\
(172 \pm 44.2)\end{array}$ & $\begin{array}{l}50.6 \pm 5.2^{*} \\
(252 \pm 25.6)\end{array}$ & $\begin{array}{l}56.1 \pm 9.8^{* * *} \\
(279 \pm 48.9)\end{array}$ \\
\hline$\alpha$-Neo Endo & $\begin{array}{l}72.1 \pm 3.6 \\
(100 \pm 4.9)\end{array}$ & $\begin{array}{l}76.6 \pm 4.5 \\
(106 \pm 6.2)\end{array}$ & $\begin{array}{c}100.6 \pm 3.6^{* * *} \\
(140 \pm 5.0)\end{array}$ & $\begin{array}{c}102.9 \pm 6.5^{* * *} \\
(143 \pm 9.0)\end{array}$ \\
\hline$\beta$-Neo Endo & $\begin{array}{c}3.7 \pm 0.3 \\
(100 \pm 7.8)\end{array}$ & $\begin{array}{c}3.7 \pm 0.3 \\
(100 \pm 8.1)\end{array}$ & $\begin{array}{c}4.3 \pm 0.3 \\
(119 \pm 9.1)\end{array}$ & $\begin{array}{c}4.2 \pm 0.5 \\
(113 \pm 13.7)\end{array}$ \\
\hline MERGL & $\begin{array}{r}142 \pm 10.5 \\
(100 \pm 7.4)\end{array}$ & $\begin{array}{c}144 \pm 12.4 \\
(101 \pm 8.8)\end{array}$ & $\begin{array}{c}161 \pm 16.0 \\
(114 \pm 11.3)\end{array}$ & $\begin{array}{c}141 \pm 15.5 \\
(100 \pm 10.9)\end{array}$ \\
\hline \multicolumn{5}{|c|}{ Substantia nigra } \\
\hline Dyn $A(1-8)$ & $\begin{array}{l}38.6 \pm 7.4 \\
(100 \pm 19.1)\end{array}$ & $\begin{array}{l}55.7 \pm 11.3 \\
(144 \pm 29.2)\end{array}$ & $\begin{array}{l}69.8 \pm 7.6^{*} \\
(181 \pm 19.6)\end{array}$ & $\begin{array}{c}76.9 \pm 6.5^{* *} \\
(199 \pm 17.0)\end{array}$ \\
\hline Dyn A $(1-17)$ & $\begin{array}{c}9.6 \pm 1.6 \\
(100 \pm 16.5)\end{array}$ & $\begin{array}{l}16.1 \pm 2.6 \\
(167 \pm 26.9)\end{array}$ & $\begin{array}{l}26.0 \pm 2.4^{* * *} \\
(269 \pm 25.4)\end{array}$ & $\begin{array}{l}31.6 \pm 2.5^{* * *} \\
(327 \pm 26.1)\end{array}$ \\
\hline Dyn B & $\begin{array}{l}99.0 \pm 23.1 \\
(100 \pm 23.4)\end{array}$ & $\begin{array}{c}168.0 \pm 40.0 \\
(170 \pm 40.4)\end{array}$ & $\begin{array}{r}214.4 \pm 32.7^{*} \\
(217 \pm 33.0)\end{array}$ & $\begin{array}{c}229.4 \pm 21.7^{* *} \\
(232 \pm 22.0)\end{array}$ \\
\hline$\alpha$-Neo Endo & $\begin{array}{l}289 \pm 34.7 \\
(100 \pm 12.0)\end{array}$ & $\begin{array}{c}414 \pm 62.1 \\
(143 \pm 21.5)\end{array}$ & $\begin{array}{c}432 \pm 31.9 \\
(149 \pm 11.0)\end{array}$ & $\begin{array}{r}428 \pm 21.3 \\
(148 \pm 7.4)\end{array}$ \\
\hline$\beta$-Neo Endo & $\begin{array}{l}19.4 \pm 1.5 \\
(100 \pm 7.9)\end{array}$ & $\begin{array}{l}24.4 \pm 2.1 \\
(126 \pm 10.8)\end{array}$ & $\begin{array}{l}23.9 \pm 2.2 \\
(123 \pm 11.3)\end{array}$ & $\begin{array}{l}25.2 \pm 2.1 \\
(130 \pm 10.8)\end{array}$ \\
\hline \multicolumn{5}{|l|}{ Hippocampus } \\
\hline Dyn A(1-8) & $\begin{array}{c}7.2 \pm 1.4 \\
(100 \pm 19.2)\end{array}$ & $\begin{array}{l}10.6 \pm 2.8 \\
(146 \pm 39.1)\end{array}$ & $\begin{array}{c}9.0 \pm 1.6 \\
(124 \pm 22.9)\end{array}$ & $\begin{array}{c}7.5 \pm 2.0 \\
(104 \pm 27.3)\end{array}$ \\
\hline Dyn A(1-17) & $\begin{array}{l}24.4 \pm 1.9 \\
(100 \pm 7.9)\end{array}$ & $\begin{array}{l}27.4 \pm 3.6 \\
(112 \pm 14.8)\end{array}$ & $\begin{array}{l}28.0 \pm 2.7 \\
(115 \pm 11.1)\end{array}$ & $\begin{array}{l}28.9 \pm 5.6 \\
(118 \pm 22.8)\end{array}$ \\
\hline Dyn B & $\begin{array}{l}28.7 \pm 2.4 \\
(100 \pm 8.5)\end{array}$ & $\begin{array}{l}36.1 \pm 4.3 \\
(126 \pm 15.0)\end{array}$ & $\begin{array}{l}33.9 \pm 2.9 \\
(118 \pm 10.2)\end{array}$ & $\begin{array}{l}29.5 \pm 5.7 \\
(103 \pm 19.7)\end{array}$ \\
\hline$\alpha$-Neo Endo & $\begin{array}{l}43.7 \pm 8.5 \\
(100 \pm 19.4)\end{array}$ & $\begin{array}{l}54.3 \pm 7.6 \\
(124 \pm 17.3)\end{array}$ & $\begin{array}{l}50.5 \pm 7.7 \\
(116 \pm 17.7)\end{array}$ & $\begin{array}{l}45.7 \pm 6.2 \\
(105 \pm 14.3)\end{array}$ \\
\hline
\end{tabular}

was recovered, with approximately $85 \%$ of this material eluting in a single peak consistent with $\alpha$-Neo Endo standard. The magnitude of the amphetamine response was found to be nearly identical in sieved and unsieved pooled samples $(155 \%$ and $154 \%$ of control, respectively). It therefore appears that the high concentration and diminished effect seen with $\alpha$-Neo Endo were not due to artifacts in the radioimmunoassay of raw samples.

Animals given a single injection of amphetamine (5.0 $\mathrm{mg} / \mathrm{kg}$ ) once per day for 7 days, and sacrificed $1 \mathrm{~h}$ following the final injection (7 days-no rest), showed almost no changes in Prodyn peptides when compared with saline control animals. There was no significant effect on any peptide in the striatum or hippocampus as revealed by $t$-tests; in the substantia nigra only Dyn A(1-17) was increased. Fig. 3 shows a direct comparison between animals sacrificed $1 \mathrm{~h}$ and animals sacrificed 24 $\mathrm{h}$ following 7 days of amphetamine treatment. There was a dramatic increase in Prodyn peptides in both the striatum and substantia nigra during the $23 \mathrm{~h}$ of rest. Significant differences were observed between $1 \mathrm{~h}$ and 24 $\mathrm{h}$ for all Prodyn peptides in the striatum except Dyn A(1-8) (Fig. 3); although no significant differences were observed in the substantia nigra, the 24-h time point was greater than the 1-h time point for all Prodyn peptides (data not shown).

Effects of amphetamine on 'precursor-product' relationships. Treatment with amphetamine for 7 days caused changes in relationships between Dyn $\mathrm{A}(1-17)$ and Dyn $\mathrm{A}(1-8)$, and between $\alpha$-Neo Endo and $\beta$-Neo Endo. A dose-dependent decrease, relative to saline control, in both Dyn A(1-8)/Dyn A(1-17) and $\beta$-Neo Endo/ $\alpha$-Neo Endo occurred in the striatonigral system of animals sacrificed $24 \mathrm{~h}$ following the final amphetamine injection. 


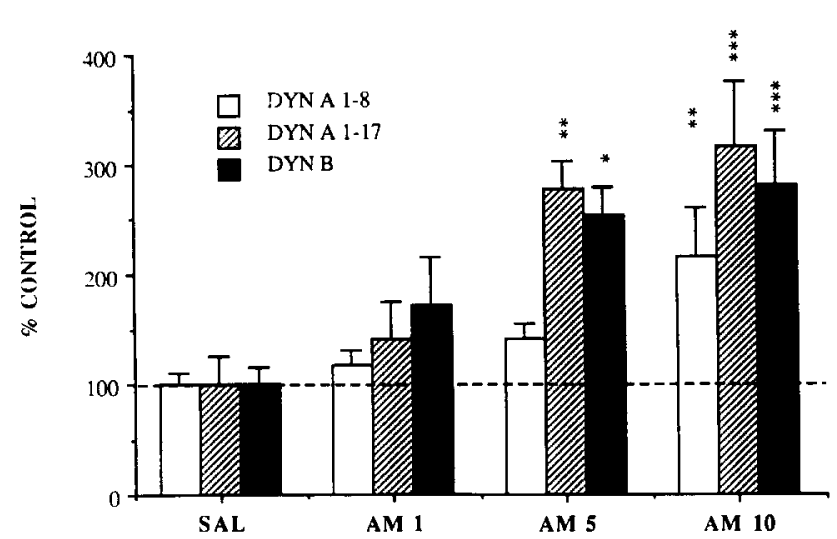

Fig. 2. Repeated amphetamine causes dose-dependent increases in striatal prodynorphin peptides. Saline (SAL) or D-amphetamine sulphate (AM; $1.0,5.0$ or $10 \mathrm{mg} / \mathrm{kg}$ ) was administered once each day for 7 days and animals sacrificed $24 \mathrm{~h}$ after the final injection; peptide concentrations were determined by radioimmunoassay. Values are expressed as mean percent control \pm S.E.M., $n=6$ animals per treatment. Significant differences from saline control were determined by analysis of variance followed by Dunnet's $t$-test for post-hoc comparisons: ${ }^{*} P<0.05,{ }^{* *} P<0.01,{ }^{* * *} P<0.005$. Similar effects were observed for all 5 prodynorphin peptides in the striatum, as well as in substantia nigra (see Table II).

Analysis of variance revealed significant changes in the substantia nigra for Dyn A(1-8)/Dyn A(1-17); decreases were similar in the striatum; however, they did not achieve significance (Fig. 4). Although changes were qualitatively similar for $\beta$-Neo Endo/ $\alpha$-Neo Endo, these changes did not achieve significance in either the striatum or the substantia nigra (Fig. 4). Animals treated for 7

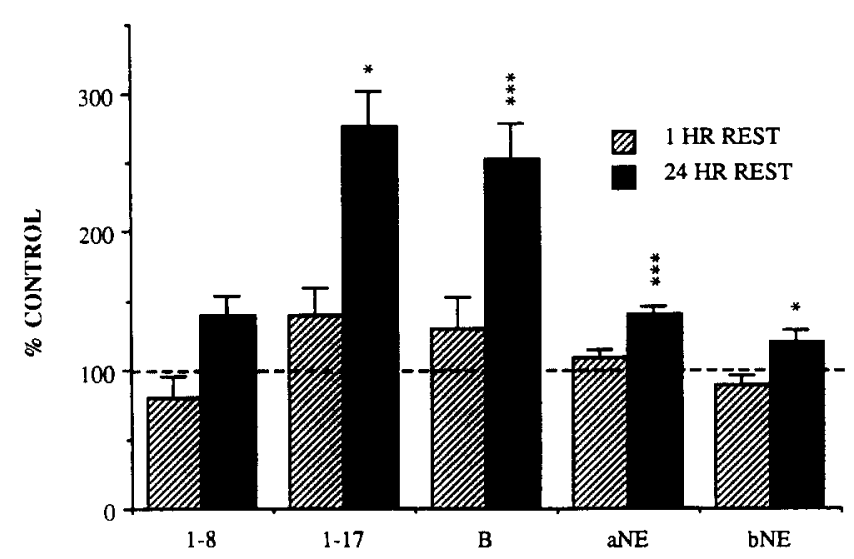

Fig. 3. Effects of repeated amphetamine administration on striatal prodynorphin peptides. Animals received a single injection of D-amphetamine sulfate $(5.0 \mathrm{mg} / \mathrm{kg})$ each for 7 days and were sacrificed $1 \mathrm{~h}$ or $24 \mathrm{~h}$ after the final injection. Values are expressed as mean percent saline control \pm S.E.M. Significant differences between $1 \mathrm{~h}$ rest and $24 \mathrm{~h}$ rest were determined by Student's $t$-test: ${ }^{*} P<0.05,{ }^{* * *} P<0.005$. No significant differences from saline control were observed at the 1-h time point. At the 24-h time point, dynorphin $\mathrm{A}(1-17)$ (1-17), dynorphin $\mathrm{B}(1-13)$ (B) and $a$-neoendorphin (aNE) were all significantly increased above saline control values. Dynorphin $\mathrm{A}(1-8)(1-8)$ and $\beta$-neo-endorphin (bNE) were slightly increased at $24 \mathrm{~h}$; however, non-significantly.
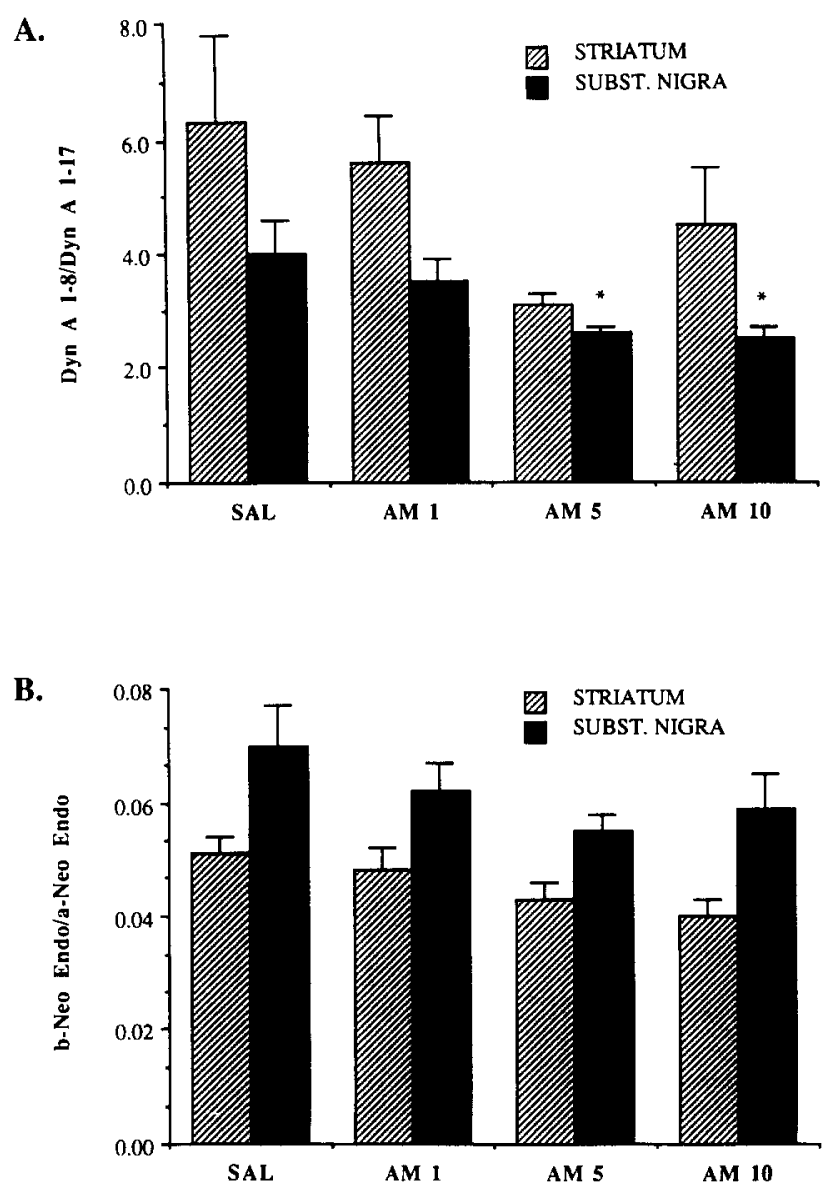

Fig. 4. Repeated amphetamine treatment alters 'precursor-product' relationships in the striatonigral system. A: changes in 'precursorproduct' relationships in the dynorphin A (Dyn A) domain. B: changes in precursor-product relationships in the neo-endorphin (Neo-Endo) domain. 'Precursor-product' relationships were determined by dividing content of the product (dynorphin $A(1-8)$ or $\beta$-neo-endorphin) by the content of its immediate 'precursor' (dynorphin A(1-17) or $\alpha$-neo-endorphin) for each animal; values are expressed as mean \pm S.E.M. Significant differences from saline control were determined by analysis of variance followed by Dunnet's $t$-test for post-hoc comparisons: ${ }^{*} P<0.05$. Note that although changes were not statistically significant in all cases, the changes were dose-dependent and in the same direction (decrease in product/precursor value).

days and sacrificed $1 \mathrm{~h}$ following the final amphetamine injection showed similar decreases in Dyn $A(1-8) / D y n$ $\mathrm{A}(1-17)$ and $\beta$-Neo Endo/ $\alpha$-Neo Endo (data not shown). No consistent changes were observed in the hippocampus. Animals sacrificed $1 \mathrm{~h}$ following a single amphetamine injection showed slight, but non-significant decreases in Dyn $A(1-8) / D y n A(1-17)$, but no consistent changes in $\beta$-Neo Endo/ $\alpha$-Neo Endo (data not shown).

Effects of haloperidol injections on Prodyn peptides. Haloperidol-injected animals showed no consistent changes in individual Prodyn peptides in the striatum, the substantia nigra or the hippocampus under any of the treatment protocols used (Tables III and IV). In animals treated for 15 days there appeared to be a trend towards 


\section{TABLE III}

Effects of acute or 4-day haloperidol treatment on peptides in striatum and substantia nigra

Animals $(n=5-6$ per group) received a single s.c. injection of sterile water $(\mathrm{VEH})$ or haloperidol (HAL; $0.25,1.0 \mathrm{or} 2.0 \mathrm{mg} / \mathrm{kg}) 1 \mathrm{~h} \mathrm{prior} \mathrm{to}$ sacrifice (Acute); or one injection each day for 4 days $(0.25,0.5,1.0$ or $2.0 \mathrm{mg} / \mathrm{kg}$ ) with sacrifice $24 \mathrm{~h}$ following the final injection (4-day). There were no significant effects on any peptide examined. Values are expressed as pmol/g wet wt. \pm S.E.M. Vaues in parentheses are percent control \pm S.E.M.

\begin{tabular}{|c|c|c|c|c|c|}
\hline & $V E H$ & $H A L 0.25$ & $H A L 0.5$ & $H A L 1.0$ & $H A L 2.0$ \\
\hline \multicolumn{6}{|l|}{ Acute haloperidol: striatum } \\
\hline Dyn $A(1-8)$ & $\begin{array}{l}35.4 \pm 2.7 \\
(100 \pm 7.6)\end{array}$ & $\begin{array}{l}35.3 \pm 3.3 \\
(100 \pm 9.3)\end{array}$ & & $\begin{array}{l}37.8 \pm 3.3 \\
(107 \pm 9.2)\end{array}$ & $\begin{array}{l}35.4 \pm 5.4 \\
(100 \pm 15.3)\end{array}$ \\
\hline Dyn A(1-17) & $\begin{array}{c}2.0 \pm 0.3 \\
(100 \pm 15.1)\end{array}$ & $\begin{array}{c}2.4 \pm 0.4 \\
(123 \pm 22.5)\end{array}$ & & $\begin{array}{l}1.7 \pm 0.4 \\
(84 \pm 22.0)\end{array}$ & $\begin{array}{l}1.5 \pm 0.5 \\
(78 \pm 24.3)\end{array}$ \\
\hline Dyn $A(1-8) /$ Dyn $A(1-17)$ & $19.1 \pm 2.3$ & $17.4 \pm 3.2$ & & $28.8 \pm 6.2$ & $29.4 \pm 6.5$ \\
\hline \multicolumn{6}{|l|}{ Substantia nigra } \\
\hline Dyn A $(1-8)$ & $\begin{array}{c}151 \pm 21.4 \\
(100 \pm 14.2)\end{array}$ & $\begin{array}{r}170 \pm 11.1 \\
(112 \pm 7.3)\end{array}$ & & $\begin{array}{c}190 \pm 34.1 \\
(126 \pm 22.5)\end{array}$ & $\begin{array}{c}195 \pm 46.4 \\
(129 \pm 30.7)\end{array}$ \\
\hline Dyn A(1-17) & $\begin{array}{l}16.3 \pm 2.5 \\
(100 \pm 15.1)\end{array}$ & $\begin{array}{l}16.3 \pm 1.0 \\
(100 \pm 6.1)\end{array}$ & & $\begin{array}{c}12.9 \pm 1.9 \\
(79 \pm 11.5)\end{array}$ & $\begin{array}{l}17.2 \pm 5.3 \\
(106 \pm 32.8)\end{array}$ \\
\hline Dyn $A(1-8) / D y n A(1-17)$ & $11.7 \pm 4.2$ & $10.6 \pm 0.9$ & & $15.0 \pm 2.2$ & $13.9 \pm 3.3$ \\
\hline \multicolumn{6}{|l|}{ 4-Day haloperidol: striatum } \\
\hline Dyn $A(1-8)$ & $\begin{array}{l}40.0 \pm 2.2 \\
(100 \pm 5.5)\end{array}$ & $\begin{array}{l}46.7 \pm 4.3 \\
(117 \pm 10.7)\end{array}$ & $\begin{array}{c}39.6 \pm 1.6 \\
(99 \pm 4.0)\end{array}$ & $\begin{array}{l}45.3 \pm 2.2 \\
(113 \pm 5.5)\end{array}$ & $\begin{array}{l}44.5 \pm 2.1 \\
(111 \pm 5.2)\end{array}$ \\
\hline Dyn A(1-17) & $\begin{array}{c}2.8 \pm 0.5 \\
(100 \pm 18.3)\end{array}$ & $\begin{array}{c}2.9 \pm 0.4 \\
(103 \pm 13.8)\end{array}$ & $\begin{array}{c}3.6 \pm 0.8 \\
(126 \pm 27.2)\end{array}$ & $\begin{array}{c}3.4 \pm 0.7 \\
(120 \pm 23.7)\end{array}$ & $\begin{array}{c}3.3 \pm 0.8 \\
(116 \pm 27.0)\end{array}$ \\
\hline Dyn A(1-8)/Dyn A(1-17) & $13.2 \pm 0.9$ & $17.6 \pm 2.9$ & $13.9 \pm 3.0$ & $16.3 \pm 3.1$ & $17.4 \pm 3.5$ \\
\hline \multicolumn{6}{|l|}{ Substantia nigra } \\
\hline Dyn $A(1-8)$ & $\begin{array}{c}154 \pm 25.9 \\
(100 \pm 16.8)\end{array}$ & $\begin{array}{c}170 \pm 28.1 \\
(110 \pm 18.2)\end{array}$ & $\begin{array}{c}169 \pm 16.3 \\
(110 \pm 10.6)\end{array}$ & $\begin{array}{c}211 \pm 39.5 \\
(137 \pm 25.6)\end{array}$ & $\begin{array}{c}205 \pm 30.0 \\
(133 \pm 19.5)\end{array}$ \\
\hline Dyn A(1-17) & $\begin{array}{l}13.9 \pm 2.9 \\
(100 \pm 20.8)\end{array}$ & $\begin{array}{c}11.7 \pm 1.5 \\
(84 \pm 10.8)\end{array}$ & $\begin{array}{c}11.8 \pm 2.9 \\
(85 \pm 20.9)\end{array}$ & $\begin{array}{l}18.2 \pm 4.6 \\
(131 \pm 32.9)\end{array}$ & $\begin{array}{l}16.1 \pm 2.4 \\
(115 \pm 17.5)\end{array}$ \\
\hline Dyn A(1-8)/Dyn A(1-17) & $17.0 \pm 7.8$ & $14.7 \pm 4.5$ & $21.1 \pm 7.3$ & $12.7 \pm 1.9$ & $13.2 \pm 1.3$ \\
\hline
\end{tabular}

decreases in Dyn $\mathrm{A}(1-17)$ and Dyn B; however, these were not statistically significant. Despite the lack of significant effect of haloperidol on individual peptides, there was a significant increase in Dyn $A(1-8) / D y n$ $A(1-17)$ in the striatum following 15 days of treatment (Table IV). There were also trends toward increases in this index following acute or 4 days treatment with haloperidol; however, these did not reach significance (Table III). In contrast to individual Prodyn peptides, MERGL increased dramatically in the striatum of animals treated for 15 days with haloperidol (Table IV).

\section{DISCUSSION}

To briefly summarize the present studies, acute amphetamine, whether given at the end of 7 days of treatment, or in the absence of previous treatment, caused depletion of striatonigral Prodyn peptides. Repeated amphetamine administration, on the other hand, caused dramatic increases in these peptides. In addition to the gross changes in peptide content, changes in 'precursor-product' relationships were observed following amphetamine treatment. No significant changes in the proenkephalin peptide MERGL were seen following treatment with amphetamine. Although no consistent changes in individual Prodyn peptides were seen following haloperidol treatment, there was a significant change in the relationship between Dyn $A(1-8)$ and Dyn $A(1-17)$. Dramatic increases in the proenkephalin peptide MERGL were observed following repeated haloperidol injections. All of these actions are discussed in more detail below.

A single, acute injection of amphetamine caused dose-dependent depletions of striatonigral Prodyn peptides. Although changes were not statistically significant for each of the peptides examined, the similar doseresponse patterns suggest that these peptides were all affected similarly by amphetamine treatment. These depletions suggest that amphetamine causes release of peptides from Prodyn neurons in the striatonigral system. Although a decrease in peptide content may be caused by either release from the neuron or by a decrease in biosynthesis, the acute nature of the challenge in the present study leads us to conclude that amphetamine indeed caused release of peptides; it is unlikely that the one-hour time span is long enough for changes in 


\section{TABLE IV}

Effects of 15-day haloperidol treatment on peptides in striatum and substantia nigra

Animals ( $n=6-7$ per group) received a single i.p. injection of sterile water (VEH) or haloperidol (HAL; $0.25,0.5,1.0$ or $2.0 \mathrm{mg} / \mathrm{kg}$ ) once each day for 15 days and were sacrificed $24 \mathrm{~h}$ after the final injection. ${ }^{*} P<0.05,{ }^{* *} P<0.025,{ }^{* * *} P<0.01$. Values are expressed as pmol/g wet wt. \pm S.E.M. Values in parentheses are percent controls \pm S.E.M.

\begin{tabular}{|c|c|c|c|c|c|}
\hline & $V E H$ & $H A L 0.25$ & $H A L 0.5$ & $H A L 1.0$ & $H A L 2.0$ \\
\hline \multicolumn{6}{|l|}{ Striatum } \\
\hline Dyn $A(1-8)$ & $\begin{array}{l}39.9 \pm 1.2 \\
(100 \pm 3.1)\end{array}$ & $\begin{array}{c}38.4 \pm 2.0 \\
(96 \pm 4.9)\end{array}$ & $\begin{array}{c}38.3 \pm 2.5 \\
(96 \pm 6.3)\end{array}$ & $\begin{array}{l}47.4 \pm 5.1 \\
(119 \pm 12.7)\end{array}$ & $\begin{array}{l}41.6 \pm 1.7 \\
(104 \pm 4.2)\end{array}$ \\
\hline Dyn A(1-17) & $\begin{array}{c}2.5 \pm 0.2 \\
(100 \pm 7.8)\end{array}$ & $\begin{array}{l}2.3 \pm 0.5 \\
(95 \pm 19.7)\end{array}$ & $\begin{array}{l}1.6 \pm 0.2 \\
(65 \pm 8.8)\end{array}$ & $\begin{array}{l}2.2 \pm 0.2 \\
(89 \pm 8.1)\end{array}$ & $\begin{array}{l}1.6 \pm 0.1 \\
(67 \pm 5.0)\end{array}$ \\
\hline Dyn A(1-8)/Dyn A(1-17) & $16.9 \pm 1.7$ & $19.4 \pm 3.1$ & $26.0 \pm 3.5^{*}$ & $21.6 \pm 1.0$ & $25.8 \pm 1.7^{*}$ \\
\hline MERGL & $\begin{array}{l}87.7 \pm 7.3 \\
(100 \pm 8.3)\end{array}$ & $\begin{array}{c}105.7 \pm 11.9 \\
(120 \pm 13.5)\end{array}$ & $\begin{array}{l}95.9 \pm 9.0 \\
(109 \pm 10.3)\end{array}$ & $\begin{array}{c}135.0 \pm 12.7^{* *} \\
(154 \pm 14.5)\end{array}$ & $\begin{array}{r}131.5 \pm 14.6^{*} \\
(150 \pm 16.7)\end{array}$ \\
\hline \multicolumn{6}{|l|}{ Substantia nigra } \\
\hline Dyn A(1-8) & $\begin{array}{c}106.1 \pm 8.8 \\
(100 \pm 8.2)\end{array}$ & $\begin{array}{c}74.9 \pm 8.9 \\
(71 \pm 8.4)\end{array}$ & $\begin{array}{c}99.2 \pm 11.4 \\
(93 \pm 10.7)\end{array}$ & $\begin{array}{r}120.9 \pm 14.4 \\
(114 \pm 13.6)\end{array}$ & $\begin{array}{c}96.6 \pm 18.9 \\
(91 \pm 17.8)\end{array}$ \\
\hline Dyn A(1-17) & $\begin{array}{l}11.6 \pm 0.3 \\
(100 \pm 2.4)\end{array}$ & $\begin{array}{c}9.7 \pm 0.4 \\
(84 \pm 3.4)\end{array}$ & $\begin{array}{l}9.1 \pm 1.0 \\
(79 \pm 8.7)\end{array}$ & $\begin{array}{c}10.2 \pm 0.6 \\
(89 \pm 5.6)\end{array}$ & $\begin{array}{c}10.3 \pm 0.7 \\
(89 \pm 5.9)\end{array}$ \\
\hline Dyn $A(1-8) /$ Dyn $A(1-17)$ & $8.2 \pm 0.5$ & $7.8 \pm 0.9$ & $9.7 \pm 0.9$ & $11.1 \pm 1.2$ & $9.1 \pm 2.4$ \\
\hline
\end{tabular}

biosynthesis to become manifest as changes in content. The fact that no effects were observed in the hippocampus, a brain region rich in dynorphins but under little influence of dopamine, suggests that the effects of amphetamine are selective to the striatonigral system.

Although decreases in striatonigral Prodyn peptides were observed at 1.0 and $5.0 \mathrm{mg} / \mathrm{kg}$, no effect was seen at $10.0 \mathrm{mg} / \mathrm{kg}$. This U-shaped dose-response curve is both interesting and puzzling; this pattern of doseresponse is common in behavioral pharmacological experiments (see ref. 55, pp. 283-337). Since high doses of amphetamine induce release of serotonin in addition to catecholamines, and since serotonin can serve as a functional antagonist of catecholamines in the striatal system (see ref. 42), it is possible that amphetamine's action on serotonin neurons serves to interfere with its effect on dynorphin release. Regardless of the lack of effect of amphetamine at this high dose, the putative release of Prodyn peptides at the lower doses is of profound interest.

It is intriguing that amphetamine caused depletion of peptides in the Prodyn cell body region (striatum) as well as the terminal region (substantia nigra). In considering the striatonigral system, one typically thinks of striatal cell bodies projecting to and terminating in the substantia nigra, without thought to potential local projections of this nucleus. In fact, striatonigral Prodyn neurons send many local collaterals within the striatum in addition to their efferent projections (J. Fallon, personal communication). The present data suggest that acute dopaminergic challenge may cause release of Prodyn peptides from local terminals in the striatum, as well as from terminals projecting to the substantia nigra. Alternatively, (or perhaps additionally) depletions in the striatum may have resulted from an increased transport of peptides from striatal Prodyn cell bodies to compensate for increased amphetamine-dependent secretion from terminals in the substantia nigra.

Animals injected with amphetamine for 7 days and rested for $24 \mathrm{~h}$ showed dramatic dose-dependent increases in all 5 Prodyn peptides in both the striatum and substantia nigra. These results are consistent with previous observations of increases in selected Prodyn peptides following repeated administration of amphetamine $22,37,48$ or apomorphine ${ }^{36,37}$. Increases in peptide content may be caused by two contrasting mechanisms: (1) a decrease in release from the neuron, leading to build-up of peptide, or (2) an increase in biosynthesis and/or processing. The present studies demonstrating depletion of peptide with acute amphetamine treatment and increases in peptide content following repeated treatment suggest that repeated release of peptides by dopaminergic challenge causes a rebound increase in biosynthesis, resulting in increased stores in striatonigral neurons, a mechanism previously proposed by $\mathrm{Li}$ et al. ${ }^{36,37}$. This phenomenon is particularly well-illustrated in the present study when comparing the animals sacrificed $1 \mathrm{~h}$ following repeated treatment with animals sacrificed $24 \mathrm{~h}$ following repeated treatment (see Fig. 3). Reflective of a rebound increase in biosynthesis, there was a dramatic increase in content of striatonigral Prodyn peptides over the $23 \mathrm{~h}$ of rest. The lack of increase seen in the animals sacrificed at the 1-h time point was presumably due to an acute release of peptides caused by the latest amphetamine challenge - 
these animals would have shown increases had they been rested prior to sacrifice. In support of an increase in biosynthesis following repeated dopaminergic challenge, an increase in striatal Prodyn mRNA has been reported following repeated apomorphine treatment ${ }^{37}$. However, it should be noted that an increase in biosynthesis does not rule out the possibility that there might also be a concomitant increase in peptide processing following repeated dopaminergic challenge.

Interestingly, although changes occurred in all 5 Prodyn peptides following amphetamine treatment, the changes were not equal in magnitude. In the present studies we compared changes in content of two intermediate peptides (Dyn A(1-17) and $\alpha$-Neo Endo) with their respective products (Dyn $\mathrm{A}(1-8)$ and $\beta$-Neo Endo), in order to assess possible selective changes in release and/or processing (for the present purposes Dyn A(1-17) can be considered the immediate 'precursor' for Dyn $\mathrm{A}(1-8)$ and $\alpha$-Neo Endo the 'precursor' for $\beta$-Neo Endo). Treatment with amphetamine for 7 days caused a dose-dependent decrease in the ratio of Dyn A(1-8):Dyn $A(1-17)$ in both the striatum and the substantia nigra, whether animals were sacrificed $1 \mathrm{~h}$ or $24 \mathrm{~h}$ following the final injection. Similar changes were observed in the $\beta$-Neo Endo: $\alpha$-Neo Endo ratio. These changes in the precursor-product relationships suggest (1) that Dyn $\mathrm{A}(1-8)$ and $\beta$-Neo Endo were preferentially released in amphetamine-treated animals in comparison to Dyn $\mathrm{A}(1-17)$ and $\alpha$-Neo Endo, and/or (2) that the processing of Dyn $\mathrm{A}(1-17)$ to Dyn $\mathrm{A}(1-8)$ and $\alpha$-Neo Endo to $\beta$-Neo Endo was decreased in treated animals.

In addition to differences in the effects of amphetamine within a particular peptide domain, there were apparent differences between domains. In examining the percent change in peptide content, it is striking that the Neo Endo domain was considerably less responsive than the Dyn A domain or the Dyn B domain to repeated amphetamine injections. Whereas 7 days of amphetamine $(10 \mathrm{mg} / \mathrm{kg})$ increased Dyn $\mathrm{A}(1-17)$ and Dyn B content in the striatum to approximately $300 \%$ of control values, this treatment increased $\alpha$-Neo Endo and $\beta$-Neo Endo to only $143 \%$ and $113 \%$ of control respectively. Similar differences in response between these domains were observed in the substantia nigra. A second observation perhaps pertinent to these findings is that $\alpha$-Neo Endo was found in higher concentrations than the Dyn A peptides or Dyn B in the striatum and substantia nigra. Molecular sieving of samples verified both the high concentration and the diminished response of $\alpha$-Neo Endo to amphetamine. Further, as noted above, the $\beta$-Neo Endo response paralleled the $\alpha$-Neo Endo response, demonstrating that the diminished effect occurred in both peptide products of the Neo Endo domain.
These findings suggest that the Neo Endo domain is indeed less responsive to repeated amphetamine treatment than other Prodyn peptide domains, when examined as a percent of control values. However, if we examine the results as absolute changes in concentration, the Neo Endo response appears much closer in magnitude to the responses of the Dyn A domain and the Dyn $B$ domain, suggesting that amphetamine may not be differentially affecting the different peptide domains; the apparent difference in response may have been an artifact of examining the results as a percent change in the face of the higher content of $\alpha$-Neo Endo. This then raises the question as to why the concentration of $\alpha-\mathrm{NeO}$ Endo is higher than the Dyn A domain or Dyn B - the structure of the Prodyn precursor predicts equimolar concentrations of these peptide domains. While it is only speculation, the most parsimonious explanation for the differences in concentration is that Dyn A and Dyn B peptides are further processed into Leu-enkephalin, while Neo Endo peptides are less likely to be further processed. This speculation is enhanced by the fact that the putative basic amino acid cleavage signals for production of Leu-enkephalin are identical for Dyn A and Dyn B (arginine-arginine) while the putative cleavage signal for Neo Endo is different (arginine-lysine). Indeed, it has been suggested that the processing enzymes that cleave at dibasic residues prefer an arginine-arginine pair to an arginine-lysine pair ${ }^{11}$. It will be of interest to further examine the regulation of the different Prodyn peptide products, together with their possible relationship to Leu-enkephalin. It should be noted, however, that while the study of the processing of Prodyn peptides into Leu-enkephalin may be of use in the substantia nigra ${ }^{64,65}$, the high concentrations of proenkephalin-derived Leuenkephalin in the striatum will interfere with such an analysis in this forebrain structure.

A question that remains insufficiently answered is: Is the functional 'tone' of the striatonigral Prodyn system altered by repeated amphetamine treatment? The changes in peptide content seen in the present experiments following repeated administration suggest that the ratios of releasable products, and therefore the functional activity in this system, may indeed be altered by treatment with amphetamine. Further, if we examine the depletion of Prodyn peptides resulting from an amphetamine challenge, the profile seen in animals sacrificed 1 $h$ after multiple injections is quite different from the profile seen in animals sacrificed $1 \mathrm{~h}$ after a single injection. When amphetamine was administered to animals that had received multiple injections of amphetamine, apparent depletion of total Prodyn immunoreactivity was not dramatically different from a single injection; however, the depletion of Dyn B was twice that 


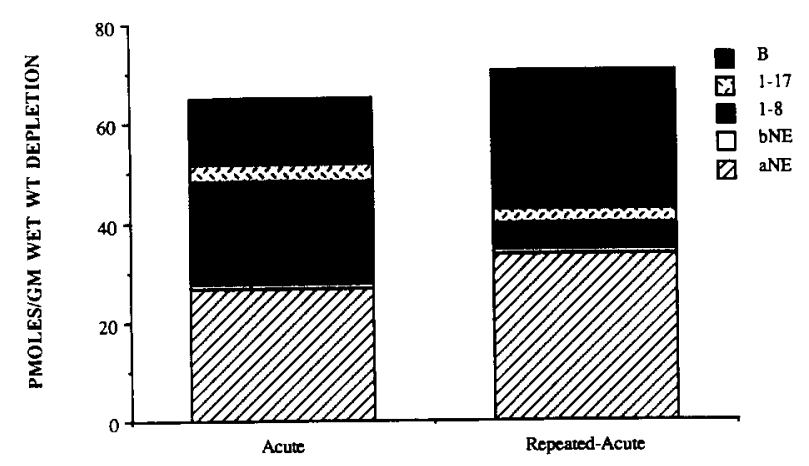

Fig. 5. Effects of amphetamine challenge on striatal Prodyn peptides in naive animals and in animals with a history of repeated amphetamine injections. The 'Acute' bar represents the amphetamine-dependent depletion of peptides in naive animals that received a single injection of amphetamine (content of individual peptides in animals that received a single injection of amphetamine, $5.0 \mathrm{mg} / \mathrm{kg}, 1 \mathrm{~h}$ prior to sacrifice was subtracted from animals that received saline). The 'Repeated-Acute' bar represents the amphetamine-dependent depletion of peptides in animals that received 7 daily injections of amphetamine (content of individual peptides in animals that received a single injection of amphetamine, $5.0 \mathrm{mg} / \mathrm{kg}$, each day for 7 days and were sacrificed $1 \mathrm{~h}$ after the final injection was subtracted from animals that received a single injection each day for 7 days and were sacrificed $24 \mathrm{~h}$ after the final injection). Values are expressed as $\mathrm{pmol} / \mathrm{g}$ wet weight depletion.

seen following a single injection, and the depletion of Dyn $A(1-8)$ was one-fourth that seen following a single injection (Fig. 5). Thus, reflecting the different changes in content of the different Prodyn peptides, there may be a relative increase in the depletion of Dyn $B$ and a relative decrease in the depletion of $\operatorname{Dyn} A(1-8)$ in animals with a previous history of repeated amphetamine treatment. The relatively greater $x$-receptor affinity of Dyn $B^{9}$ suggests that the striatonigral system will receive much greater kappa activation on amphetamine challenge following repeated injections of amphetamine than following a single, acute injection. Experiments are presently underway to more specifically examine whether changes in released products occur following repeated administration of amphetamine.

Although there is no direct evidence in the present study that the effects of amphetamine are mediated by dopamine, an abundance of evidence supports this contention. First, as noted above, although amphetamine has important actions on both dopamine and norepinephrine neurons, norepinephrine appears to play an insignificant role in amphetamine-induced effects in the nigrostriatal system. Further, no changes in Prodyn peptides were observed in the hippocampus, a brain structure densely innervated by norepinephrine terminals. Moreover, similar changes in striatonigral Dyn $A(1-8)$ have been reported following treatment with the direct acting dopamine agonist, apomorphine, which were reversed by the dopamine antagonist haloperidol ${ }^{36}$. While not included in the present paper, we have preliminary evidence suggesting that the effects of repeated amphetamine administration on Prodyn peptides are attenuated by coadministration of haloperidol. The available evidence thus suggests that the effects of amphetamine on striatonigral prodynorphin peptides are indeed mediated by dopamine.

In contrast to amphetamine, haloperidol alone had no significant effects on individual striatonigral Prodyn peptides, whether injected acutely, or repeatedly for 4 or 15 days. These results are consistent with reports by Peterson and Robertson ${ }^{48}$ and $\mathrm{Li}$ et al ${ }^{36}$, that repeated injections of haloperidol had no effects on Dyn A(1-8); however, they are at odds with reports by Quirion et al. ${ }^{51}$ and Tandon et al. ${ }^{57}$, that repeated haloperidol injections dramatically altered striatonigral Prodyn peptides. The reason for the differences in the effect of haloperidol observed in these studies is presently unclear. Despite the lack of significant effects of haloperidol on individual peptides, however, this system was not entirely unaffected by treatment with the dopamine antagonist in the present study. Following 15 days treatment there was a change in the 'precursor-product' relationship between Dyn A(1-17) and Dyn A(1-8): a significant dosedependent increase in the Dyn A(1-8):Dyn A(1-17) ratio was observed in the striatum, which was paralleled in the substantia nigra. In addition, although not significant, there were suggestions of similar changes following acute or 4-day treatment with haloperidol. The changes, as would be expected, were opposite to those seen following acute or chronic treatment with amphetamine. These results suggest that haloperidol causes a subtle decrease in release and/or increase in processing of Prodyn peptides, such that the more processed products accumulate more rapidly than the intermediate peptides. Thus, while we were unable to replicate the significant effects of haloperidol on Prodyn peptides previously observed in our laboratory ${ }^{57}$ or those seen by Quirion et al. ${ }^{51}$, we found that blockade of dopamine receptors did indeed affect the striatonigral Prodyn system.

The effects of amphetamine and haloperidol treatment on Prodyn peptides are in stark contrast to the effects of these drugs on the proenkephalin peptide MERGL. While acute or repeated injections of amphetamine caused dramatic effects on Prodyn peptides, there was no effect of amphetamine treatment on MERGL. In addition, while haloperidol treatment had relatively subtle effects on Prodyn peptides, repeated administration of this drug caused dramatic increases in MERGL; previous studies have shown increases in enkephalin peptides, precursors and messenger RNA following haloperidol treatment ${ }^{4,6,16,27,28,41,44,58}$. Thus, whereas Prodyn peptides appear to be highly affected by increases in dopaminergic activity and little affected by decreases, the 
opposite pattern appears to be true for proenkephalin peptides. These results indicate that there are distinct mechanisms involved in the regulation by dopamine of the two opioid peptide families in the striatum. These findings are consistent with suggestions that enkephalins and dynorphins may reside in different populations of neurons within the striatum ${ }^{5.18}$. The effects of dopaminergic drugs on both Prodyn and proenkephalin peptides can be contrasted with the effects of these compounds on another striatal peptide system, substance P. Striatonigral substance $\mathbf{P}$ is increased by dopamine agonists ${ }^{20,53}$, but unlike Prodyn peptides, decreased by dopamine antagonists $^{20,21,26}$. The latter dissociation between Prodyn peptides and substance $P$ is very interesting in light of recent demonstrations that Prodyn peptides and substance $\mathrm{P}$ may be colocalized in striatal cell bodies ${ }^{1.3 .52}$.

There are some interesting functional issues that should be discussed regarding these results. The present observation that Prodyn peptides may be released following acute injections of amphetamine suggests that these transmitters might be involved in some of the behavioral consequences of acute amphetamine administration. Indeed, the fact that several amphetaminedependent behaviors are blocked by the opiate receptor antagonist naloxone suggests that endogenous opioids may mediate these behaviors. Of particular note are naloxone antagonism of the rewarding effects of amphetamine, as determined by facilitation of self-stimulation ${ }^{13}$. ${ }^{25.59}$ or by conditioned place preference ${ }^{59}$, as well as naloxone blockade of amphetamine-stimulated locomotor behaviors, such as increased activity ${ }^{23.24}$ and turning behavior ${ }^{10}$. These behaviors are of particular significance to the present study due to the demonstrated role of the striatum in their expression; evidence suggests that the rewarding effects and the locomotor stimulating effects of amphetamine are mediated by the ventral striatum (or nucleus accumbens; see refs. $15,30,63$ ), while amphetamine-dependent turning is mediated primarily by the dorsal striatum (or caudate-putamen; see ref. 31). In addition to the possible involvement in the acute effects of amphetamine, the changes in Prodyn peptides seen following repeated amphetamine suggests that these peptides might be involved in the behavioral manifestations resulting from multiple injections of this drug. Two distinct syndromes are seen following repeated adminis-

\section{REFERENCES}

1 Anderson, K.D. and Reiner, A., Extensive co-occurrence of substance $\mathrm{P}$ and dynorphin in striatal projection neurons in rat, Soc. Neurosci. Abstr., 14 (1988) 76.

2 Angrist, B. and Sudilovsky, A., Central nervous system stimulants: historical aspects and clinical effects. In L.L. Iversen, S.D. Iversen and S.H. Snyder (Eds.), Stimulants, Handbook of Psychopharmacology, Vol. 11, Plenum, New York, 1978, pp. tration of amphetamine. The first, the withdrawal syndrome, is expressed soon after discontinuation of administration and is characterized by decreased activity. lethargy and depression ${ }^{2}$. The second, known as sensitization or reverse tolerance, is manifest as an increased behavioral response to an amphetamine challenge $\mathrm{e}^{49,50,54}$. The dramatic increases in Prodyn peptides seen in the present experiments suggest the possibility that Prodyn peptides might play a role in the development or the expression of the amphetamine withdrawal syndrome or amphetamine sensitization. Experiments are currently underway to examine the possible role of Prodyn peptides in each of these syndromes. In contrast to the dramatic effects of amphetamine on Prodyn peptides, the relatively subtle effects of haloperidol suggest that these peptides may play a limited role in the functional changes that occur following treatment with dopamine antagonists. Instead, proenkephalin peptides may play an important role in the effects of these drugs.

In conclusion, the effects of amphetamine and haloperidol observed in the present experiments suggest that nigrostriatal dopamine has the ability to regulate striatonigral Prodyn neurons. While a relatively subtle effect of the dopamine antagonist haloperidol suggests that tonic activity of dopamine is not important in the regulation of striatonigral Prodyn, the dramatic effects of the indirectly acting dopamine agonist amphetamine demonstrate the ability of increased dopamine activity to profoundly influence this peptide system. Furthermore, the present results emphasize the contrasting regulation of proenkephalin and Prodyn peptides by dopamine in the striatum. The nigrostriatal-striatonigral loop may prove to be a valuable model for the study of the regulation of Prodyn peptides, as well as proenkephalin peptides, in the central nervous system.

Acknowledgements. We would like to thank Giulio Baldrighi for his contributions to this project and for his years of service to this laboratory, and acknowledge him for his many years of service to the behavioral and brain sciences. Thanks to Dr. C.J. Evans of Stanford University for providing the $\beta$-neo-endorphin antiserum. This work was supported in part by NIDA National Research Service Award DA05336 (K.A.T.), a fellowship from the Medical Research Council of Canada (R.D.) and NIDA Grant DA02265, NIMH Grant MH422251 and the T. Raphael Research Fund (H.A.). A preliminary report of this work was presented at the 1987 Society for Neuroscience Meeting in New Orleans, LA ${ }^{(x)}$.

$99-165$

3 Besson, M.-J., Graybiel, A.M. and Quinn, B., Coexistence of dynorphin B-like and substance P-like immunoreactivity in striatal neurons in the cat, Soc. Neurosci. Abstr., 12 (1986) 876

4 Blanc. D., Cupo, A., Castanas, E., Bourhim, N., Giraud, P., Bannon, M.J. and Eiden, L.E., Influence of acute, subchronic and chronic treatment with neuroleptic (haloperidol) on enkephalins and their precursors in the striatum of rat brain, Neuropeptides, 5 (1985) 567-570. 
5 Chesselet, M.-F. and Graybiel, A.M., Met-enkephalin-like and dynorphin-like immunoreactivities of the basal ganglia of the cat, Life Sci., 33 Suppl. 1 (1983) 37-40.

6 Chou, J., Tang, J., Yang, H.-Y.T. and Costa, E., Increase of striatal Met $^{5}$-enkephalin-arg ${ }^{6}$-phe ${ }^{7}$ (YGGFMRF) content elicited by long-term treatment with haloperidol, J. Pharmacol. Exp. Ther., 229 (1984) 171-174.

7 Christensson-Nylander, I., Herrera-Marschitz, M., Staines, W., Hökfelt, T., Terenius, L., Ungerstedt, U., Cuello, C., Oertel, W.H. and Goldstein, M., Striatonigral dynorphin and substance $P$ pathways in the rat. I. Biochemical and immunohistochemical studies, Exp. Brain Res., 64 (1986) 169-192.

8 Civelli, O., Douglass, J., Goldstein, A. and Herbert, E., Sequence and expression of the rat prodynorphin gene, Proc. Natl. Acad. Sci. U.S.A., 82 (1982) 4291-4295.

9 Corbett, A.D., Paterson, S.J., McKnight, A.T., Magnan, J. and Kosterlitz, H.W., Dynorphin(1-8) and dynorphin(1-9) are ligands for the $x$-subtype of opiate receptor, Nature (Lond.), 299 (1982) 79-81.

10 Dettmar, P.W., Cowan, A. and Walter, D.S., Naloxone antagonizes behavioral effects of $D$-amphetamine in mice and rats, Neuropharmacology, 17 (1978) 1041-1044.

11 Docherty, K. and Steiner, D.F., Post-translational proteolysis in polypeptide hormone biosynthesis, Ann. Rev. Physiol., 44 (1982) 625-638.

12 Dray, A., The striatum and substantia nigra: a commentary on their relationships, Neuroscience, 4 (1979) 1407-1439.

13 Esposito, R.U., Perry, W. and Kornetsky, C., Effects of D-amphetamine and naloxone on brain stimulation reward, Psychopharmacology, 69 (1980) 187-191.

14 Fallon, J.H., Leslie, F.M. and Cone, R.I., Dynorphin-containing pathways in the substantia nigra and ventral tegmentum: a double labeling study using combined immunofluorescence and retrograde tracing, Neuropeptides, 5 (1985) 457-460.

15 Fibiger, H.C. and Phillips, A.G., Reward, motivation, cognition: psychobiology of mesotelencephalic dopamine systems. In V.B. Mountcastle, F.E. Bloom and S.R. Geiger (Eds.), Handbook of Physiology - The Nervous System IV, American Physiological Society, Bethesda, MD, 1986, pp. 647-675.

16 George, S.R. and Kertesz, M., Met-enkephalin concentrations in striatum respond reciprocally to alterations in dopamine neurotransmission, Peptides, 8 (1987) 487-492.

17 Goldstein, A., Tachibana, S., Lowney, L.I., Hunkapillar, M. and Hood, L., Dynorphin(1-13), an extraordinarily potent opioid peptide, Proc. Natl. Acad. Sci. U.S.A., 76 (1979) 6666-6670.

18 Graybiel, A.M. and Chesselet, M.-F., Compartmental distribution of striatal cell bodies expressing Met-enkephalin-like immunoreactivity, Proc. Natl. Acad. Sci. U.S.A., 81 (1984) 7980-7984.

19 Graybiel, A.M. and Ragsdale, C.W., Biochemical anatomy of the striatum. In P.C. Emson (Ed.), Chemical Neuroanatomy, Raven, New York, 1983, pp. 427-504.

20 Hanson, G.R., Alphs, L., Pradhan, S. and Lovenberg, W. Response of striatonigral substance $P$ systems to a dopamine receptor agonist and antagonist, Neuropharmacology, 20 (1981) 541-548.

21 Hanson, G.R., Alphs, L., Wolf, N., Levine, R. and Lovenberg, W. Haloperidol-induced reduction of nigral substance P-like immunoreactivity: a probe for the interactions between dopamine and substance $\mathrm{P}$ neuronal systems, J. Pharmacol. Exp. Ther., 218 (1981) 568-574.

22 Hanson, G.R., Merchant, K.M., Letter, A.A., Bush, L. and Gibb, J.W., Methamphetamine-induced changes in the striatalnigral dynorphin system: role of $\mathrm{D}_{1}$ and $\mathrm{D}_{2}$ receptors, Eur. $J$. Pharmacol., 144 (1987) 245-246.

23 Hitzemann, R., Currell, J., Hom, D. and Loh, H., Effects of naloxone on $\mathrm{D}$-amphetamine- and apomorphine-induced behavior, Neuropharmacology, 21 (1982) 1005-1011.

24 Holtzman, S.G., Behavioral effects of separate and combined administration of naloxone and D-amphetamine, J. Pharmacol. Exp. Ther., 180 (1974) 51-60.

25 Holtzman, S.G., Comparison of the effects of morphine, pentazocine, cyclazocine and amphetamine on intracranial selfstimulation in the rat, Psychopharmacology, 46 (1976) 223-227.

26 Hong, J.S., Yang, H.-Y.T. and Costa, E., Substance P content of substantia nigra after chronic treatment with anti-schizophrenic drugs, Neuropharmacology, 17 (1978) 83-85.

27 Hong, J.S., Yang, H.-Y.T., Fratta, W. and Costa, E., Rat striatal methionine-enkephalin content after chronic treatment with cataleptogenic and non-cataleptogenic anti-schizophrenic drugs, J. Pharmacol. Exp. Ther., 205 (1978) 141-147.

28 Hong, J.S., Yang, H.-Y.T., Gillin, J.C., DiGuilio, A.M., Fratta, W. and Costa, E., Chronic treatment with haloperidol accelerates the biosynthesis of enkephalins in rat striatum, Brain Research, 160 (1979) 192-195.

29 Kakidani, H., Furutani, Y., Takahashi, H., Noda, M., Morimoto, Y., Hirose, T., Asai, M., Inayama, S., Nakanishi, S. and Numa, S., Cloning and sequence analysis of cDNA for porcine $\beta$-neo-endorphin/dynorphin precursor, Nature (Lond.), 298 (1982) 245-249.

30 Kelley, A.E. and Stinus, L., Neuroanatomical and neurochemical substrates of affective behavior. In N.A. Fox and R.J. Davidson (Eds.), The Psychobiology of Affective Development, Lawrence Erlbaum Associates, Hillsdale, NJ, 1984, pp. 1-75.

31 Kelly, P.H., Drug-induced motor behavior. In L.L. Iversen, S.D. Iversen and S.H. Snyder (Eds.), Drugs, Neurotransmitters, and Behavior, Handbook of Psychopharmacology, Vol. 8, Plenum, New York, 1977, pp. 295-331.

32 Kubota, Y., Inagaki, S. and Kito, S., Innervation of substance $P$ neurons by catecholaminergic terminals in the neostriatum, Brain Research, 375 (1986) 163-167.

33 Kubota, Y., Inagaki, S., Kito, S., Takagi, H. and Smith, A.D., Ultrastructural evidence of dopaminergic input to enkephalinergic neurons in rat neostriatum, Brain Research, 367 (1986) 374-378.

34 Kubota, Y., Inagaki, S., Kito, S. and Wu, J.Y., Dopaminergic axons directly make synapses with GABAergic neurons in the rat neostriatum, Brain Research, 406 (1987) 147-156.

35 Kubota, Y., Inagaki, S., Shimada, S., Kito, S., Eckenstein, F. and Tohyama, M., Neostriatal cholinergic neurons receive direct synaptic inputs from dopaminergic axons, Brain Research, 413 (1987) $179-184$.

$36 \mathrm{Li}$, S., Sivam, S.P. and Hong, J.S., Regulation of the concentration of dynorphin $A(1-8)$ in the striatonigral pathway by the dopaminergic system, Brain Research, 398 (1986) 390-392.

37 Li, S.J., Sivam, S.P., McGinty, J.F., Jiang, H.K., Douglass, J., Calavetta, L. and Hong, J.S., Regulation of the metabolism of striatal dynorphin by the dopaminergic system, J. Pharmacol. Exp. Ther., 246 (1988) 403-408.

38 McLean, S., Bannon, M.J., Zamir, N. and Pert, C.B., Comparison of the substance $\mathrm{P}$ - and dynorphin-containing projections to the substantia nigra: a radioimmunocytochemical and biochemical study, Brain Research, 361 (1985) 185-192.

39 Minamino, N., Kangawa, K., Chino, N., Sakakibara, S. and Matsuo, H., $\beta$-Neo-endorphin, a new hypothalamic 'big' Leuenkephalin of porcine origin: its purification and the complete amino acid sequence, Biochem. Biophys. Res. Commun., 99 (1981) 864-870.

40 Minamino, N., Kangawa, K., Fukuda, A. and Matsuo, H., A new opioid octapeptide related to dynorphin from porcine hypothalamus, Biochem. Biophys. Res. Commun., 95 (1980) $1475-1481$.

41 Mocchetti, I., Schwartz, J.P. and Costa, E., Use of mRNA hybridization and radioimmunoassay to study the mechanisms of drug-induced accumulation of enkephalins in rat brain structures, Mol. Pharmacol., 28 (1985) 86-91.

42 Moore, K.E., Amphetamines: biochemical and behavioral actions in animals. In L.L. Iversen, S.D. Iversen and S.H. Snyder (Eds.), Stimulants, Handbook of Psychopharmacology, Vol. 11, 
Plenum, New York, 1978, pp. 41-98.

43 Nakao, K., Suda, M., Sakamoto, M., Yoshimasa, T., Morii, N., Ikeda, Y., Yanaihara, C., Yanaihara, N., Numa, S. and Imura, $\mathrm{H}$., Leumorphin is a novel endogenous opioid peptide derived from proenkephalin B, Biochem. Biophys. Res. Commun., 117 (1983) 695-701.

44 Normand, E., Popovici, T., Onteniente, B., Fellmann, D., Piatier-Tonneau, D., Auffray, C. and Bloch, B., Dopaminergic neurons of the substantia nigra modulate preproenkephalin $A$ gene expression in rat striatal neurons, Brain Research, 439 (1988) 39-46.

45 Nylander, I. and Terenius, L., Chronic haloperidol and clozapine differentially affect dynorphin peptides and substance $P$ in basal ganglia of the rat, Brain Research, 380 (1986) 34-41

46 Palkovits, M., Brownstein, M.J. and Zamir, N., On the origin of dynorphin $\mathrm{A}$ and $\alpha$-neo-endorphin in the substantia nigra, Neuropeptides, 4 (1984) 193-199.

47 Penney, J.B. and Young, A.B., Speculations on the functional anatomy of basal ganglia disorders, Ann. Rev. Neurosci., 6 (1983) 73-94.

48 Peterson, M.R. and Robertson, H.A., Effect of dopaminergic agents on levels of dynorphin(1-8) in rat striatum, Prog. Neuro-Psychopharmacol. Biol. Psychiat, 8 (1984) 725-728.

49 Post, R.M., Intermittent versus continuous stimulation: effect of time interval on the development of sensitization or tolerance, Life Sci., 26 (1980) 1275-1282.

50 Post, R.M., Central stimulants: clinical and experimental evidence on tolerance and sensitization. In Y. Israel, F.B. Glaser, H. Kalant, R.E. Pophano, W. Schmidt and R.G. Smart (Ed.), Research Advances in Alcohol and Drug Problems, Vol. 6 , Plenum, New York, 1981, pp. 1-65.

51 Quirion, R., Gaudreau, P., Martel, J.-C., St-Pierre, S. and Zamir, N., Possible interactions between dynorphin and dopaminergic systems in rat basal ganglia and substantia nigra, Brain Research, 331 (1985) 358-362.

52 Reiner, A., The co-occurrence of substance P-like immunoreactivity and dynorphin-like immunoreactivity in striatopallidal and striatonigral projection neurons in birds and reptiles, Brain Research, 371 (1986) 155-161.

53 Ritter, J.K., Schmidt, C.J., Gibb, J.W. and Hanson, G.R, Increases of substance P-like immunoreactivity within striatalnigral structures after subacute methamphetamine treatment, $J$. Pharmacol. Exp. Ther., 229 (1984) 487-492.
54 Robinson, T.E. and Becker, J.B., Enduring changes in brain and behavior produced by chronic amphetamine administration: a review and evaluation of animal models of amphetamine psychosis, Brain Res. Rev., 11 (1986) 157-198.

55 Seiden, L.S. and Dykstra, L.A., Psychopharmacology: A Biochemical and Behavioral Approach, Van Nostrand Reinhold, New York, 1977

56 Seizinger, B.R., Höllt, V. and Herz, A., Evidence for the occurrence of the opioid octapeptide dynorphin(1-8) in the neurointermediate pituitary of rats, Biochem. Biophys. Res. Commun., 102 (1981) 197-205.

57 Tandon, R., Day, R., Kelsey, J.E., Watson, S.J. and Akil, H., The effect of haloperidol on pro-dynorphin end products in the rat striatum and substantia nigra, Soc. Neurosci. Abstr., 12 (1986) 234.

58 Tang, F., Costa, E. and Schwartz, J.P., Increase of proenkephalin mRNA and enkephalin content of rat striatum after daily injection of haloperidol for 2 to 3 weeks, Proc. Natl. Acad. Sci. U.S.A., 80 (1983) 3841-3844.

59 Trujillo, K.A., Endogenous Opioids and Reinforcement: Effects of Opiate Antagonists on Intracranial Self-Stimulation Behavior and in Conditioned Place Preference, Doctoral Dissertation, University of California, Irvine, 1985.

60 Trujillo, K.A., Day, R. and Akil, H., Increases in striatonigral dynorphins following repeated amphetamine injections, Soc. Neurosci. Abstr., 13 (1987) 637.

61 Vincent, S., Hökfelt, T., Christensson, I. and Terenius, L., Immunohistochemical evidence for a dynorphin immunoreactive striatonigral pathway, Eur. J. Pharmacol., 85 (1982) 251-252.

62 Watson, S.J. and Akil, H., Immunocytochemistry of peptides. In J.L. Barker and J.F. McKelvey (Eds.), Current Methods in Cellular Neurobiology, Wiley, New York, 1982, pp. 111-131.

63 Watson, S.J., Trujillo, K.A., Herman, J.P. and Akil, H., Neuroanatomical and neurochemical substrates of drug seeking behavior. In A. Goldstein (Ed.), Molecular and Cellular Aspects of the Drug Addictions, Springer, New York, 1989, pp. 29-91.

64 Zamir, N., Palkovitz, M., Weber, E., Meyer, E. and Brownstein, M.J., A dynorphinergic pathway of Leu-enkephalin production in rat substantia nigra, Nature (Lond.), 307 (1984) 643-645.

65 Zamir, N. and Quirion, R., Dynorphinergic pathways of Leu-enkephalin production in rat brain, Neuropeptides, 5 (1985) 441-444. 